\title{
CALIBRATION/VALIDATION OF LANDSAT-DERIVED OCEAN COLOUR PRODUCTS IN BOSTON HARBOUR
}

\author{
Nima Pahlevan ${ }^{\mathrm{a}, \mathrm{b}, *}$, Patrick Sheldon $^{\mathrm{c}}$, Francesco Peri $^{\mathrm{c}}$, Jianwei Wei ${ }^{\mathrm{c}}$, Zhehai Shang $^{\mathrm{c}}$, \\ Qingsong Sun ${ }^{\mathrm{c}}$, Robert F. Chen ${ }^{\mathrm{c}}$, Zhongping Lee ${ }^{\mathrm{c}}$, Crystal B. Schaaf ${ }^{\mathrm{c}}$ John R. Schott ${ }^{\mathrm{d},}$ and Thomas Loveland \\ aNASA Goddard Space Flight Center, 8800 Greenbelt Road, Greenbelt, MD 20771, USA - nima.pahlevan@nasa.gov \\ ${ }^{\mathrm{b}}$ Science Systems and Applications, Inc., 10210 Greenbelt Road, Lanham, MD 20706, USA - nima.pahlevan@nasa.gov \\ ${ }^{c}$ University of Massachusetts Boston, 100 Morrissey Blvd. Boston, MA 02125, USA - (Crystal.Schaaf, Patrick.Sheldon001, \\ Qingsong.Sun, Jianwei.Wei, ZhongPing.Lee, Bob.Chen, Francesco.Peri, Zhehai.Shang001) @umb.edu \\ ${ }^{\mathrm{d}}$ Rochester Institute of Technology, 54 Lomb Memorial Dr Rochester NY 14623, USA - schott@cis.rit.edu \\ eU.S. Geological Survey, EROS Center, 47914 252nd Street Sioux Falls SD 57030, USA - loveland@usgs.gov
}

\section{Commission VI, WG VIII/9}

KEY WORDS: Landsat, ocean colour, coastal waters, algorithm development, water constituents,

\begin{abstract}
:
The Landsat data archive provides a unique opportunity to investigate the long-term evolution of coastal ecosystems at fine spatial scales that cannot be resolved by ocean colour (OC) satellite sensors. Recognizing Landsat's limitations in applications over coastal waters, we have launched a series of field campaigns in Boston Harbor and Massachusetts Bay (MA, USA) to validate OC products derived from Landsat-8. We will provide a preliminary demonstration on the calibration/validation of the existing OC algorithms (atmospheric correction and in-water optical properties) to enhance monitoring efforts in Boston Harbor. To do so, Landsat optical images were first compared against ocean colour products over high-latitude regions. The in situ cruise data, including optical data (remote sensing reflectance) and water samples were analyzed to obtain insights into the optical and biogeochemical properties of near-surface waters. Along with the cruise data, three buoys were deployed in three locations across the Harbor to complement our database of concentrations of chlorophyll $a$, total suspended solids (TSS), and absorption of colour dissolved organic matter (CDOM). The data collected during the first year of the project are used to develop and/or tune OC algorithms. The data will be combined with historic field data to map in-water constituents back to the early 1990's. This paper presents preliminary analysis of some of the data collected under Landsat- 8 overpasses.
\end{abstract}

\section{INTRODUCTION}

The Operational Land Imager (OLI) onboard Landsat-8 outperforms the heritage Landsat optical sensors in two ways: a) the radiometric resolution (12 bit versus 8 bit) and b) the spectral coverage (four visible channels versus three). The OLI is a pushbroom sensor, which allows for higher signal-to-noise ration (SNR) than that of the Thematic Mapper (TM) and the Enhanced Thematic Mapper Plus (ETM+) (Pahlevan et al. 2014). In addition, the new coastal/aerosol (CA) band cantered at $443 \mathrm{~nm}$ allows for measuring inherent optical properties (IOPs) of the water column at the chlorophyll $a$ peak absorption. The major advantage of OLI over existing ocean colour missions like the Moderate Resolution Imaging Spectroradiometer (MODIS) is its relatively fine spatial sampling permitting opportunities for mapping optically active components (OACs) of upper water column in inland (lakes, ponds, rivers, wetlands, streams) and coastal waters. The Landsat revisit time (16 days) is significantly improved with the very recent launch of the MultiSpectral Imager (MSI) aboard Sentinel-2A (and Sentinel-2B in the near future). Although this satellite constellation is intended for monitoring landuse/landchange, within the next 10-15 years, the triplet of sensors will be providing a well-calibrated, robust set of data allowing limnologists and ecologists as well as water resources managers to monitor aquatic systems at high-frequent revisit time with minimal costs.

Motivated by the availability of these valuable assets, we have launched a series of field cruises under Landsat- 8 overpasses in the Boston Harbour (Massachusetts, USA) to calibrate and validate ocean colour products derived from OLI. In addition, we present the most recent intercomparisons with ocean colour missions to evaluate OLI calibration status over bodies of water.

\section{METHODOLOGY}

\subsection{OLI calibration}

The foremost requirement for high-quality ocean colour products is to ensure that the instrument is well-calibrated and remains temporally stable. In general, the on-orbit calibration uncertainties of ocean colour mission are required to be better than $\pm 0.5 \%$ to meet climate-quality products. Designed for land applications, the OLI calibration requirement is $4 \%$ in the topof-atmosphere (TOA) reflectance domain $\left(\rho_{t}\right)$. Here, we use sensor products with ocean colour science capability to evaluate the calibration status of OLI at TOA. These ocean colour sensors include MODIS on-board Aqua (MODISA) and the Visible Infrared Imaging Radiometer Suite (VIIRS), which are vicariously calibrated and have been reprocessed over their lifetime by the NASA ocean colour-processing group (OBPG).

The OLI-VIIRS and OLI-MODISA intercomparisons are made at near-simultaneous nadir overpasses (n-SNOs) where the two sensors observe the same ground spot with a time lag. This time lag ranges from two minutes to 25 minutes. Across each OLI scene, several locations (termed calibration site) can be found where intercomparisons can be made. In order to perform this intercomparison, several steps are taken to ensure a robust analysis:

- Accept only per-footprint intercomparisons for which the difference in the near-infrared (NIR) TOA reflectances falls below a certain threshold.

- Model MODISA and VIIRS footprints to accurately average OLI $30-\mathrm{m}$ pixels

- Model differences in the relative spectral response functions of the sensors using forward radiative transfer modelling (RTM) 
Since April 2013, when OLI data became available, there are nearly 100 OLI-VIIRS and OLI-MODISA pairs that allow for robust intercomparison analyses.

\subsection{In situ data collection}

During the summer and fall of 2015, four different cruises were conducted under Landsat- 8 overpasses. The radiometric data (downwelling and upwelling light) were collected using the Hyper-OCR radiometers (Satlantic Corp). The radiometer measuring the upwelling radiance (above water) is augmented with a dark-painted cone made of acrylic to block the skyreflected light (Lee et al. 2013). The inherent optical properties (IOPs) of water and the radiometric measurements were made at three stations across Boston Harbour. In addition, three buoys equipped with optical instrumentations (including backscattering at $550 \mathrm{~nm}, \mathrm{CDOM}$ fluorescence and $\mathrm{Chl}$ fluorescence) were deployed from mid-spring to the fall of 2015. During the cruises, we also measured optical backscattering using a towed instrument package the MiniShuttle. The combination of all these data could provide sufficient field data to validate OLI-derived ocean colour products. Fig. 1 illustrates the locations of the stations (buoys) and the transect travelled under the Landsat overpass on June $17^{\text {th }} 2015$. The physical/biogeochemical parameters are given as a function of salinity.)

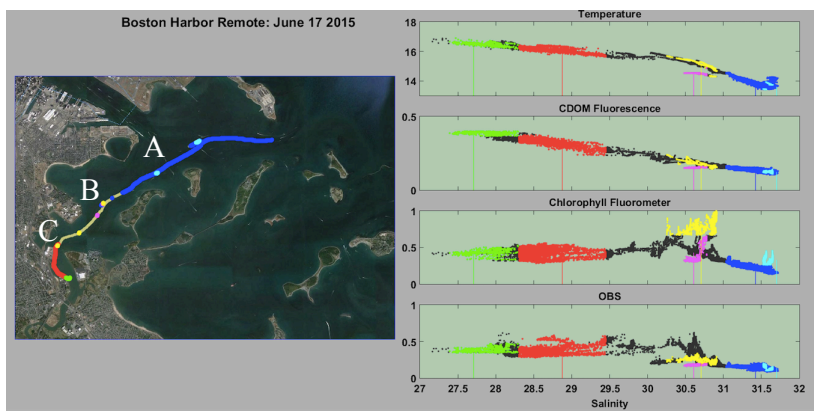

Figure 1. The cruise track along which in-situ data was collected under Landsat-8 overpass. The measured data are provided as a function of salinity along the transect. The buoys A, B, and C have been indicated.

\subsection{OLI data processing}

The SeaDAS processing system (http://seadas.gsfc.nasa.gov) was used to perform the atmospheric correction (ACO) and to derive products such as chlorophyll $a$ (Franz et al. 2015). We

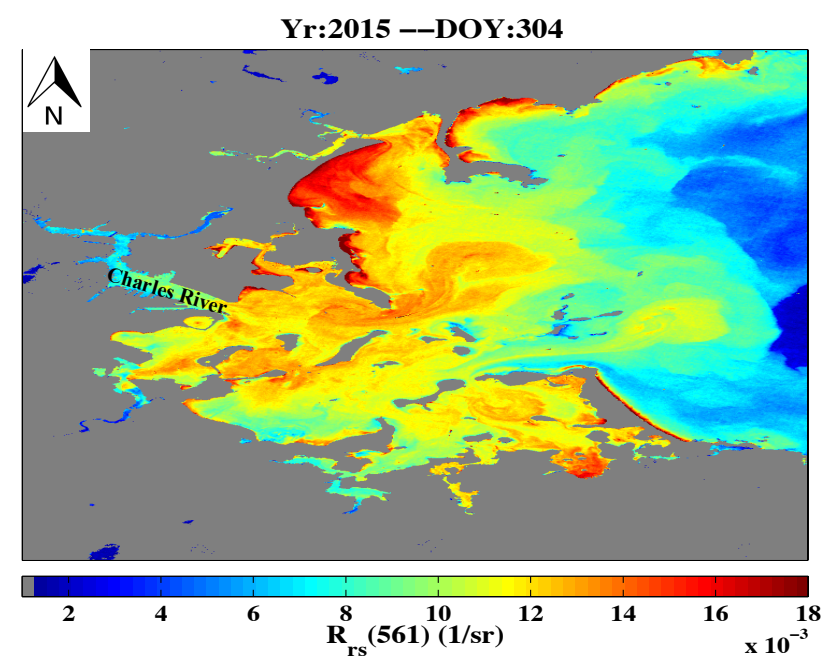

Figure 2. The remote sensing reflectance products at $561 \mathrm{~nm}$ over the Boston Harbour on 10/31/2015. Various physical features (swirls and eddies) are captured with high radiometric fidelity of OLI imagery.
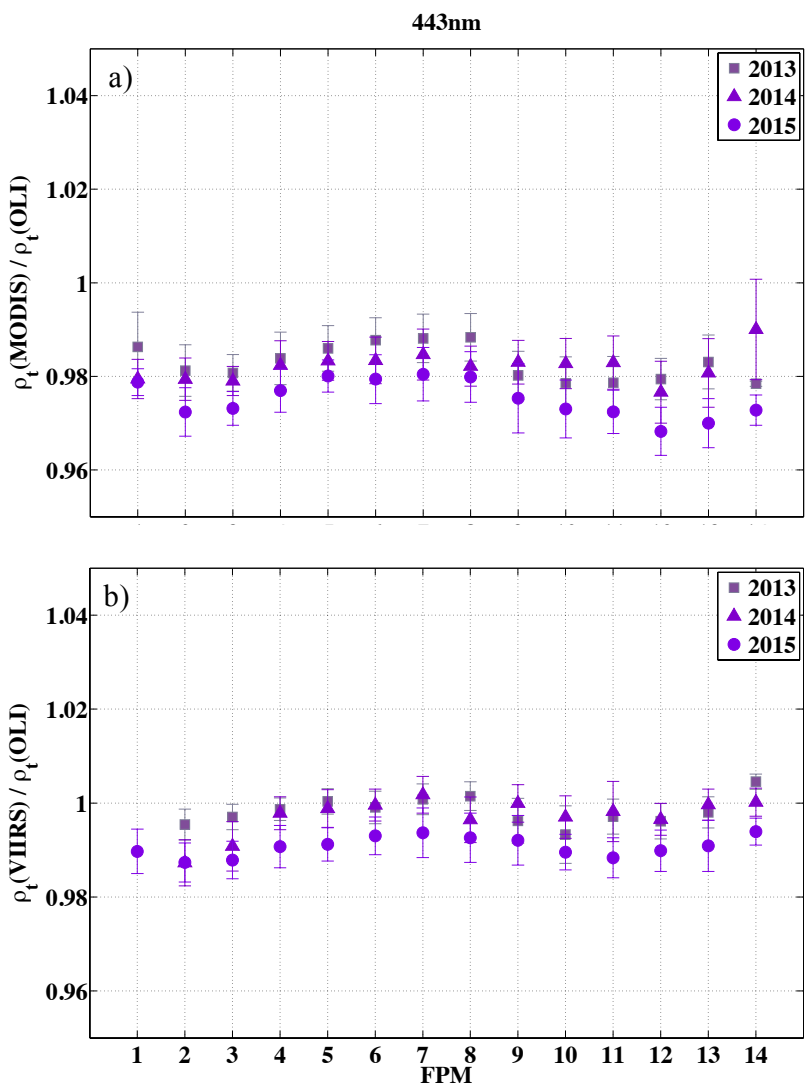

Figure 3. The ratio of OLI and MODIS (a) and VIIRS (b) TOA reflectances across the OLI focal plane shown as a function of the focal plane modules (FPM). The error bars indicate the intercomparison uncertainty.

used the combination of near infrared (NIR) and shortwave infrared (SWIR) bands for the atmospheric correction (Vanhellemont and Ruddick 2015). In order to reduce noisy retrievals, a $3 \times 3$-element averaging filter was run over the OLI TOA imagery. The aerosol correction was therefore conducted on a per-pixel basis. Fig. 2 illustrates the remote sensing reflectance at $561 \mathrm{~nm}$, i.e., $R_{r s}(561)$. Note that the processing system incorporates per-pixel imaging geometry (Storey et al. 2014), which is essential to accounting for differences in OLI's band-specific, per-pixel viewing geometry. Note that OLI's focal plane is formed from 14 different focal plane modules (Figure 3; FPMs) that view the ground at different azimuth angles. The other products generated via SeaDAS include total absorption and total particulate backscattering, Chl a, and the diffuse attenuation coefficients at $490 \mathrm{~nm}$.

\section{RESULTS}

\subsection{TOA intercomparison}

The OLI-MODISA and OLI-VIIRS intercomparisons made at high-latitude, northern hemisphere are shown in Fig. 3. The gains are in the form of $\rho_{t}(\mathrm{X}) / \rho_{t}(\mathrm{OLI})$ given only for the 443 $\mathrm{nm}$ channel and have been derived independently over the course of the three years. Note that in the above ratio (Fig. 3), X represents MODISA (a) and VIIRS (b). The relative gains derived from the two sets of intercomparisons are found to be consistent. However, there are three critical considerations worth further discussions. First, the average gains computed for the two sets differ, on average, by $1.2 \%$ implying that the MODISA and VIIRS absolute calibrations in the $443 \mathrm{~nm}$ channel may be different. Second, there is $\sim 0.7 \%$ change in the OLI's absolute radiometric response across the focal plane. Third, it is found that the mean annual gain have changed in 
2015 relative to 2013 or 2014 . This change amounts, on average, to less than $0.7 \%$. In addition, the estimated uncertainties associated with the approach combined with VIIRS/MODISA calibration uncertainties are found to be, on average, $<0.6 \%$. The results assert that the n-SNO-based intercomparisons are robust and can be further extended to other channels, and to other missions that are not designed specifically for aquatic applications.

\subsection{Field validation}

The validation efforts presented here include evaluation of the atmospherically corrected products $\left(R_{r s}\right)$ and Chl $a$. Fig. 4 illustrates the $R_{r s}$ matchups collected over three stations (buoys) in Boston Harbour. There is an excellent agreement between OLI and in situ data over buoys A and B, however, the products are found inconsistent with in situ measurements for buoy C. Our analysis of the image products revealed that adjacency effects have resulted in such a mismatch between the retrievals and in situ observations. This is because buoy $\mathrm{C}$ (which has historically been collecting data at the proximity of the Neponset River) is only $\sim 80 \mathrm{~m}$ distant from land features. The adjacency effect may have become higher at low tide conditions.

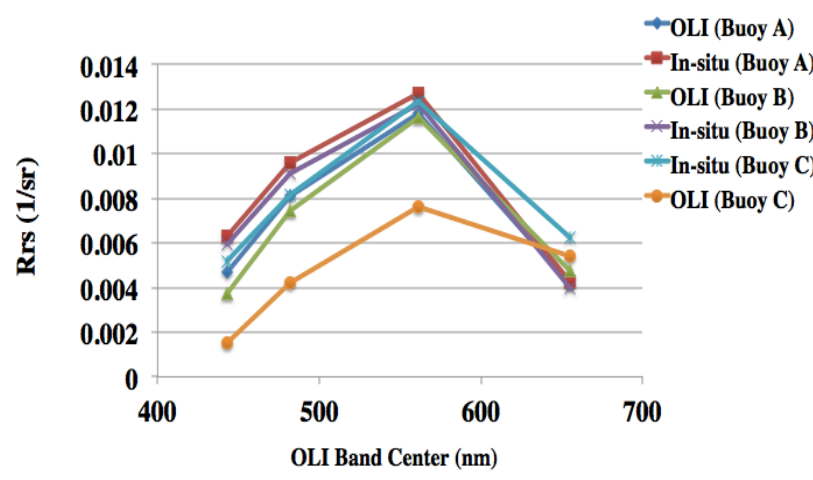

Figure 4. Comparison of the OLI-derived $\boldsymbol{R}_{r s}$ and spectrally resampled in-situ $\boldsymbol{R}_{r s}$ at three stations (Buoys). Overall, there is a very good agreement between OLI retrievals and the in-situ measurements.

The quantitative evaluations (in the form of percent difference, $\%$ ) are tabulated in Table 1 . It is shown that there is, on average, a $\sim 15 \%$ underestimation of $R_{r s}$ in most of the OLI channels. As described, the discrepancy in $R_{r s}$ for buoy $\mathrm{C}$ increases due to adjacency effects.

Table 1. The matchup analysis for the OLI-derived products shown in $\%$.

\begin{tabular}{|c|c|c|c|c|}
\hline & $R_{r S}(443)$ & $R_{r S}(482)$ & $R_{r S}(561)$ & $R_{r S}(655)$ \\
\hline Buoy A & -25.59 & -15.82 & -6.74 & -2.08 \\
\hline Buoy B & -36.81 & -18.41 & -5.11 & 19.24 \\
\hline Buoy C & -71.27 & -48.54 & -38.05 & -13.16 \\
\hline
\end{tabular}

With the underestimations of $R_{r s}$, it is expected that the retrieved $\mathrm{Chl}$ a products are overestimated. Fig. 5 shows OLIderived $\mathrm{Chl}$ a products computed based on the OC3 algorithm, i.e., based on $R_{r s}(482) / R_{r s}(561)$ for these trophic coastal waters. The empirical coefficients have been updated using SeaBASS data (Franz et al. 2015). It is clearly seen that OLI can provide $\mathrm{Chl}$ a maps giving insights into the relative productivity at small spatial scales that cannot be resolved by MODIS or VIIRS. The Boston Harbour Chl a map reveals that the productivity across the Harbour is relatively uniform spatially with exceptions at the proximity of river/stream discharges. That said, it should be noted that the $\mathrm{Chl} a$ product includes instrument artifacts, i.e., striping. This is associated with the

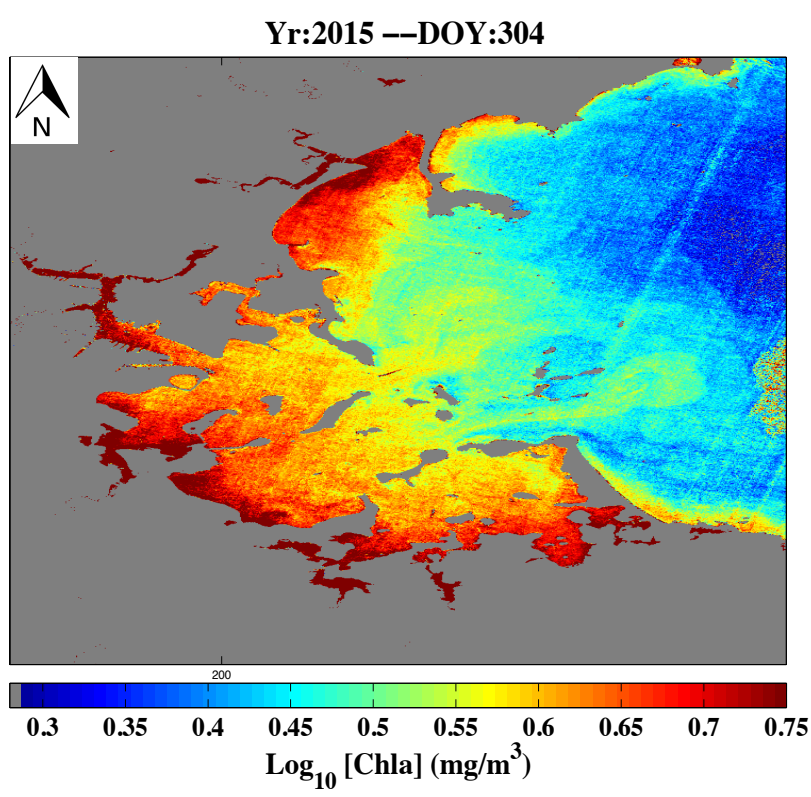

Figure 5. The OLI-derived Chl a products over Boston Harbour and Massachusetts Bay. While OLI provides clues on the relative productivity, it contains striping induced by instrument artifacts as well as per-pixel NIR-SWIR based aerosol correction.

OLI's inherent pushbroom imaging method, which requires a large number of detectors to cover the entire $185 \mathrm{~km}$ swath.

\section{DISCUSSION}

This paper investigated the consistency and validity of the OLI products over turbid coastal waters. For the $443 \mathrm{~nm}$ channel, the OLI TOA products are found to be in a better agreement with VIIRS TOA data than that of MODISA. Amongst all of the OLI's FPMs, FPM 6 and 7 (around the centre of the swath) are the most consistent with the ocean colour missions. Our study area was also located over the OLI scene centre (Path 12 / row 31). While three matchups do not provide robust statistics to examine OLI-derived $R_{r s}$ products, according to the intercomparison results, there are two likely reasons for the relatively large differences tabulated in Table 1 . First, we have not fully evaluated OLI calibration in the SWIR channels, which have been used in the atmospheric correction process. Uncertainties in the calibration of OLI's SWIR/NIR bands propagate to $R_{r s}$ products. Second, it is possible that the underestimation in $R_{r s}(443)$ is related to imperfect aerosol correction, which has not been elaborated here for brevity. This difference may be expected due to the presence of absorbing aerosols in urban areas, which, of course, requires TOA radiometric measurements in the UV portion of the spectrum. Again, there is more evidence needed to make a strong conclusion towards enhancing moderate-resolution ocean colour products over regions such as Boston Harbour. In the future, minimizing these uncertainties will further improve water quality products derived from Landsat-Sentinel-2 constellation over rivers, streams, harbours, lagoons, and estuaries across the globe.

\section{ACKNOWLEDGEMENTS}

Support for this work has been provided by the MIT SeaGrant program under the Award \# 2015-R/RC-140. We also acknowledge the support by Ed Masuoka of the Terrestrial Information Systems Lab at NASA GSFC. 


\section{REFERENCES}

Franz, B.A., Bailey, S.W., Kuring, N., \& Werdell, P.J. (2015). Ocean color measurements with the Operational Land Imager on Landsat-8: implementation and evaluation in SeaDAS. Journal of Applied Remote Sensing, 9, 096070-096070

Lee, Z., Pahlevan, N., Ahn, Y.-H., Greb, S., \& O'Donnell, D. (2013). Robust approach to directly measuring water-leaving radiance in the field. Applied Optics, 52, 1693-1701

Pahlevan, N., Lee, Z., Wei, J., Schaff, C., Schott, J., \& Berk, A. (2014). On-orbit radiometric characterization of OLI (Landsat8) for applications in aquatic remote sensing. Remote Sensing of Environment, 154, 272-284

Storey, J., Choate, M., \& Lee, K. (2014). Landsat 8 Operational Land Imager on-orbit geometric calibration and performance. Remote Sensing, 6, 11127-11152

Vanhellemont, Q., \& Ruddick, K. (2015). Advantages of high quality SWIR bands for ocean colour processing: Examples from Landsat-8. Remote Sensing of Environment, 161, 89-106 